\title{
Genome-Wide Association Mapping of Rice Resistance Genes Against Magnaporthe oryzae Isolates from Four African Countries
}

\author{
Emmanuel M. Mgonja, Elias G. Balimponya, Houxiang Kang, Maria Bellizzi, Chan Ho Park, Ya Li, Robert Mabagala, \\ Clay Sneller, Jim Correll, Stephen Opiyo, Nicholas J. Talbot, Thomas Mitchell, and Guo-Liang Wang
}

First, fourth, fifth, sixth, tenth, twelfth, and thirteenth authors: Department of Plant Pathology, and second and eighth authors: Department of Horticulture and Crop Science, The Ohio State University, Columbus; third and thirteenth authors: State Key Laboratory for Biology of Plant Diseases and Insect Pests, Institute of Plant Protection, Chinese Academy of Agricultural Sciences, Beijing; seventh author: Department of Crop Science and Production, Sokoine University of Agriculture, Morogoro, Tanzania; ninth author: Department of Plant Pathology, University of Arkansas, Fayetteville; and eleventh author: School of Biosciences, University of Exeter, UK.

Accepted for publication 27 May 2016.

\begin{abstract}
Mgonja, E. M., Balimponya, E. G., Kang, H., Bellizzi, M., Park, C. H., Li, Y., Mabagala, R., Sneller, C., Correll, J., Opiyo, S., Talbot, N. J., Mitchell, T., and Wang, G.-L. 2016. Genome-wide association mapping of rice resistance genes against Magnaporthe oryzae isolates from four African countries. Phytopathology 106:1359-1365.

Rice blast disease is emerging as a major constraint to rice production in Africa. Although a traditional gene-tagging strategy using biparental crosses can effectively identify resistance $(R)$ genes or quantitative trait loci (QTL) against Magnaporthe oryzae, the mapping procedure required is time consuming and requires many populations to investigate the genetics of resistance. In this report, we conducted a genome-wide association study (GWAS) to rapidly map rice genes conferring resistance against eight

M. oryzae isolates from four African countries. We inoculated 162 rice cultivars, which were part of the rice diversity panel 1 (RDP1) and were previously genotyped with the 44,000 single-nucleotide polymorphism (SNP) chip, with the eight isolates. The GWAS identified 31 genomic regions associated with blast resistance $(R A B R)$ in the rice genome. In addition, we used polymerase chain reaction analysis to confirm the association between the Pish gene and a major $R A B R$ on chromosome 1 that was associated with resistance to four $M$. oryzae isolates. Our study has demonstrated the power of GWAS for the rapid identification of rice blast $R$ or QTL genes that are effective against African populations of $M$. oryzae. The identified SNP markers associated with $R A B R$ can be used in breeding for resistance against rice blast in Africa.
\end{abstract}

The popularity of rice as a food crop is rapidly increasing throughout Africa. Rice consumption in urban areas of Africa has significantly increased, and per capita consumption has doubled since 1970 (Muthayya et al. 2014). The demand for rice is becoming higher because of a general dietary shift away from traditional foods such as maize, cassava, yam, millet, and sorghum (Nayar 2014). The current per capita consumption of rice in Africa is estimated to be $23.3 \mathrm{~kg} /$ annum (FAO 2012). Despite this increase in rice consumption, only $40 \%$ of the rice consumed in Africa is produced in Africa (IRRI 2013).

As in other rice-growing areas of the world, rice blast disease caused by the fungus Magnaporthe oryzae (Bourett and Howard 1990; Ribot et al. 2008) is a major constraint for rice production in Africa. The disease is spreading in both lowland and upland ecosystems (Séré et al. 2013). Deployment of resistant varieties combined with the use of good cultural practices remains the most promising approach to blast disease management (Maclean and Dawe 2002; Mew et al. 2004; Savary et al. 2012).

Single resistance $(R)$-gene-mediated resistance is qualitative and provides complete resistance against specific races of $M$. oryzae, exhibiting a gene-for-gene interaction with pathogens. In contrast to complete resistance, partial resistance is quantitatively inherited and controlled by multiple quantitative trait loci (QTL); in addition,

Corresponding author: G.-L. Wang; E-mail address: wang.620@osu.edu

*The $e$-Xtra logo stands for "electronic extra" and indicates that eight supplementary figures and five supplementary tables are published online.

http://dx.doi.org/10.1094/PHYTO-01-16-0028-R

(C) 2016 The American Phytopathological Society partial resistance is considered to be more durable than $R$-genemediated resistance (Mundt 2014). Because of its clear resistance phenotype and dominant expression, however, complete resistance has long been favored over partial resistance by plant breeders. In all, 60 major $R$ genes and 17 minor $R$ genes against $M$. oryzae have been mapped in the rice genome, and 22 of these have already been cloned (Liu et al. 2014; Wang et al. 2014b). The effectiveness of these $R$ genes against the $M$. oryzae populations in Africa has not been extensively tested. Although mutational and conventional breeding techniques, including pedigree selection, anther culture, wide hybridization between Oryza glaberrima and $O$. sativa, and backcrossing have been widely used in Africa (Habarurema et al. 2012; Luzi-Kihupi et al. 2009; Singh et al. 2001), the efficiency of breeding for disease resistance has been low on the continent because of inefficient field screening, high pathogen population pressure, and lack of information on the prevailing $M$. oryzae population structure and virulence (Tharreau et al. 2009; Zeigler et al. 1994).

Traditional gene mapping methods using $\mathrm{F}_{2}$ populations and recombinant inbred lines have been used to localize target genes in many crop plants. Although it will continue to be an important tool for gene mapping, this approach is time consuming and provides only low mapping resolution. These limitations, however, can be reduced with the use of the genome-wide association study (GWAS) approach (Abdurakhmonov and Abdukarimov 2008). Unlike traditional gene-tagging efforts using biparental crosses, GWAS uses natural populations or germplasm collections and linkage disequilibriumbased association to rapidly map target genes in a large collection of diverse genotypes. Application of GWAS for the dissection of complex traits in maize, rice, foxtail millet, and sorghum has been reported in recent years (Huang et al. 2010; Jia et al. 2013; Kump et al. 2011; Li et al. 2012; Morris et al. 2013). For example, GWAS 
was used to identify multiple genes that potentially control complex traits such as flowering time, leaf size, leaf angle, and disease resistance (Buckler et al. 2009; Poland et al. 2011; Tian et al. 2011).

In rice, researchers have used GWAS with high-density singlenucleotide polymorphism (SNP) chips and low-coverage sequencing methods to identify genes and QTL associated with traits related to abiotic stress, grain quality, and agronomic performance. In a recent GWAS, 366 diverse indica accessions with 0.8 million SNP were inoculated with $16 \mathrm{M}$. oryzae isolates. In total, 30 loci associated with blast disease resistance were identified, and 4 of these loci were linked to previously mapped $R$ genes while 26 were novel candidate genes that may contribute to defense responses (Wang et al. 2014a).

Our laboratory recently used the rice diversity panel 1 (RDP1), containing 0.7 million SNP and five $M$. oryzae isolates, to identify 97 loci associated with blast resistance $(L A B R)$. In all, 15 of these $L A B R$ were linked to known $R$ gene loci and 82 were new. Some of the $L A B R$ are strongly associated with $R$ and defense genes encoding nucleotide-binding site leucine-rich repeats (NBS-LRR), defense-related proteins, transcription factors, and receptor-like protein kinases (Kang et al. in press). In this study, we used 162 RDP1 cultivars (70 indica and 92 temperate japonica) (Eizenga et al. 2013). These cultivars were inoculated with eight isolates from four African countries. Association mapping showed that 31 regions associated with blast resistance $(R A B R)$ in the rice genome were involved in the resistance against the eight isolates. Polymerase chain reaction (PCR) analysis revealed that a major $R A B R$ on chromosome 1 is associated with resistance to four $M$. oryzae isolates. Our study demonstrates the effectiveness of GWAS for the rapid identification of $R$ or QTL genes in rice and provides linked SNP markers for breeding for resistance against rice blast in Africa.

\section{MATERIALS AND METHODS}

Plant and fungal materials. The 162 O. sativa accessions (70 indica and 92 temperate japonica) used in this study were part of the RDP1 (Eizenga et al. 2013) and were obtained from the Genetic Stocks-Oryza Collection at the United States Department of Agriculture-Agricultural Research Service Dale Bumpers National Rice Research Center. These cultivars were collected from 82 countries. Seed were increased in a greenhouse at the Ohio State University in summer 2013. The eight $M$. oryzae isolates used in this study were among those collected in a survey of $M$. oryzae populations conducted in summer 2013 in four African countries: Tanzania, Uganda, Kenya, and Burkina Faso (unpublished results). We inoculated four rice cultivars ('IR64', 'Toride', 'Nipponbare', and 'CO-39') with different levels of resistance with 60 isolates. Based on their pathogenicity on these cultivars, we selected eight isolates for this study: TZ-01 and TZ-12 from Tanzania, UG-05 and UG-11 from Uganda, KE-14 and KE-37 from Kenya, and BF-05 and BF-27 from Burkina Faso.

Random amplified polymorphic DNA and PCR analysis. We used random amplified polymorphic DNA (RAPD) markers to assess the genetic variability of the eight most virulent isolates (Govarthanan et al. 2011; Williams et al. 1990). Fungal DNA was extracted from the mycelia using the cetyltrimethylammonium bromide method (Bashir et al. 2014). DNA was quantified with a Nanodrop spectrophotometer. PCR amplifications were performed in a $25-\mu 1$ reaction mixture consisting of genomic DNA at $50 \mathrm{ng} / \mu \mathrm{l}$, $1 \times$ reaction buffer (Promega Corp.), $0.25 \mathrm{mM} \mathrm{dNTP,} 0.2 \mu \mathrm{M}$ random primer, $2.5 \mu \mathrm{M} \mathrm{MgCl}_{2}$, and $1 \mathrm{U}$ of Taq polymerase. The amplification included one denaturing cycle of $4 \mathrm{~min}$ at $94^{\circ} \mathrm{C}$; followed by 45 cycles of $1 \mathrm{~min}$ at $94^{\circ} \mathrm{C}, 1 \mathrm{~min}$ at $40^{\circ} \mathrm{C}$, and $1 \mathrm{~min}$ at $72^{\circ} \mathrm{C}$; and a final extension step of $2 \mathrm{~min}$ at $72^{\circ} \mathrm{C}$. The amplified products were resolved by electrophoresis on a $1.4 \%$ agarose gel using TAE buffer (45 mM Tris-acetate and $1 \mathrm{mM}$ EDTA, $\mathrm{pH}$ 8.0) at $100 \mathrm{~V}$ for $2 \mathrm{~h}$. A 1-kb ladder was included as a molecular size marker. Gels were stained with an ethidium bromide solution
$(0.5 \mu \mathrm{g} / \mathrm{ml})$ and band patterns were visualized with UV light. Definite, bright polymorphic bands of various molecular weights that were generated by the RAPD markers were scored " 1 " for presence and " 0 " for absence. Euclidean Distance, Complete Linkage in Minitab software was used to perform a cluster analysis and to create a dendrogram of the eight $M$. oryzae isolates based on RAPD marker scores.

PCR analysis of RABR_2 was done using 10 resistant and 15 susceptible rice cultivars from RDP1 based on our blast inoculation results. The PCR reaction started with a denaturation step for $3 \mathrm{~min}$ at $95^{\circ} \mathrm{C}$; followed by 33 cycles of $30 \mathrm{~s} \mathrm{~min}$ at $95^{\circ} \mathrm{C}, 30 \mathrm{~s}$ min at $58^{\circ} \mathrm{C}$ for annealing of primers, and $1 \mathrm{~min}$ at $72^{\circ} \mathrm{C}$ for extension; and stopped after a final extension step of $72^{\circ} \mathrm{C}$ for $10 \mathrm{~min}$. The amplified products were resolved by electrophoresis on a $1.4 \%$ agarose gel using TAE buffer at $100 \mathrm{~V}$ for $2 \mathrm{~h}$. A 1-kb ladder was included as a molecular size marker. Gels were staining with an ethidium bromide solution $(0.5 \mu \mathrm{g} / \mathrm{ml})$ and band patterns were visualized with UV light.

Evaluation of blast resistance phenotypes. Rice seedlings and fungal cultures were grown and prepared for spray inoculation as described by Park et al. (2012). Approximately 15 rice seedlings for each of the 162 rice cultivars were grown in a growth chamber maintained with a cycle of $12 \mathrm{~h}$ of light at $26^{\circ} \mathrm{C}$ and $12 \mathrm{~h}$ of darkness at $21^{\circ} \mathrm{C}$, and $80 \%$ humidity (Park et al. 2012). Seedlings with three or four fully expanded leaves (18 to 20 days old) were sprayed with fungal spore suspensions $\left(5 \times 10^{5}\right.$ conidia/ml in $0.1 \%$ Tween 20$)$ until droplets formed on the leaves. Each sprayed seedling was kept in a plastic bag ( $\geq 90 \%$ humidity) in the dark for $24 \mathrm{~h}$, then returned to the growth chamber (Wang et al. 2012). Six days after inoculation, the seedlings were scored for disease using a 0-to-9 scale, in which 0 indicates no blast symptoms and 9 indicates severe blast symptoms (Zhu et al. 2012). The inoculation experiment was repeated two times under the same conditions. If the results from two times were different, a third inoculation was repeated to obtain a result similar to one of the previous inoculations. Data analysis was carried out using the R statistical package. The cluster analysis and principal components analysis (PCA) were conducted based on the interactions between rice genotypes and $M$. oryzae isolates.

Genome-wide association analysis. A GWAS was performed using the phenotypic data (blast disease scores) of the 162 rice accessions of the RDP1 and genotypic data (publicly available 44 K-SNP dataset) previously described by Zhao et al. (2011). A mixed linear model (MLM) (Bradbury et al. 2007) was implemented with Tassel 5.0 software (http://www.maizegenetics.net/\#!tassel/c17q9). The computational power of the MLM was further increased by using a compressed MLM, which jointly uses kinship (K) matrix and population structure $(\mathrm{Q})$ matrices The $\mathrm{K}$ matrix is the variancecovariance matrix between the individuals, and the $\mathrm{Q}$ matrix is obtained through both STRUCTURE and PCA. This model can be summarized using Henderson's matrix notation as $Y=X \beta+Z u+e$, where $Y$ is the vector of observed phenotypes; $\beta$ is an unknown vector containing fixed effects, including the genetic marker, population structure $(\mathrm{Q})$, and the intercept; $u$ is an unknown vector of random additive genetic effects from multiple background QTL for individuals/lines; $X$ and $Z$ are the known design matrices; and $e$ is the unobserved vector of random residuals (Henderson 1975; Lipka et al. 2012). Based on PERL (Christiansen et al. 2012) and its scalable vector graphics module, and using the TASSEL results as input files, we developed a Perl script to combine multiple Manhattan plot figures into an integrated one (combined Manhattan plot). Manhattan and QQ plots were produced using the R package.

\section{RESULTS}

Molecular characterization of the eight $M$. oryzae isolates. We inoculated IR64, Toride, Nipponbare, and CO-39 with $60 \mathrm{M}$. oryzae isolates that were collected from Tanzania, Kenya, Uganda, and Burkina Faso for virulence tests. Based on the inoculation results, we selected the eight most virulent isolates for inoculations in this 
study. To determine the genetic diversity of the eight $M$. oryzae isolates, we selected 10 RAPD markers based on the reproducibility of amplification. The RAPD marker sequences are shown in Supplementary Table S1. In total, 48 bright, polymorphic bands were scored. The size of the amplified fragments ranged from 300 to 3,000 bp. An example of the PCR amplification is shown in Figure 1A. Phylogenetic analysis showed that the eight isolates were genetically diverse, although those from the same country clustered together (Fig. 1B).

Resistance of the 162 RDP1 cultivars to the eight M. oryzae isolates. The 162 rice cultivars were inoculated with the eight isolates. The distributions of blast disease scores obtained by inoculating 162 cultivars with eight isolates $M$. oryzae are shown in Figure 2 and Supplementary Figures 1, 2, and 3. The disease scores were generally skewed toward susceptibility (disease score $\geq 8.0$ ) or resistance (disease score $\leq 2.0$ ). The percentages of cultivars that were resistant and susceptible to each isolate are shown in Supplementary Table S2.

Among the 162 tested cultivars, 11 were highly resistant (disease score $\leq 2.0$ ) and 15 were highly susceptible (disease score $\geq 8.0$ ) to all eight isolates (Supplementary Table S3). Cluster analysis and PCA based on disease severity indicated that the eight isolates were diverse but clustered based on the country of origin (Supplementary Figs. 4 and 5). For example, the two isolates from Tanzania (TZ-01 and TZ-12) were clustered together (approximately 75\% similarity) and also related to those from Uganda (UG-05 and UG-11), and the two isolates from Kenya (KE-14 and KE-37) were also related to each other (approximately 84\% similarity). Interestingly, the two isolates from Burkina Faso (BF05 and BF27) were quite different from the other isolates. These results are consistent with those obtained from the RAPD-based PCR analysis (Fig. 1B).

The five isolates used by Kang et al. (in press) were also included in our pathotype analysis to determine their relationship with our eight African isolates. Cluster analysis of the 13 isolates based on the pathotype data (disease scores) of 162 RPD1 cultivars showed low similarity between the eight African isolates used in our study and those used by Kang et al. (in press). Four among the five isolates used by Kang et al. (in press) - ROI-1 (from South Korea), RB22 (from China), 75-1-127 (from Colombia), and P06-6 (from the

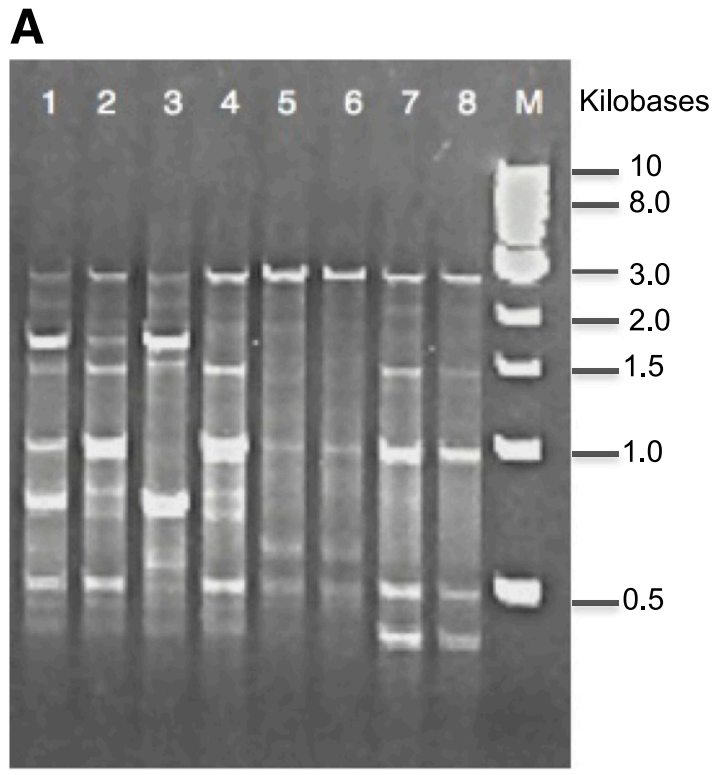

B

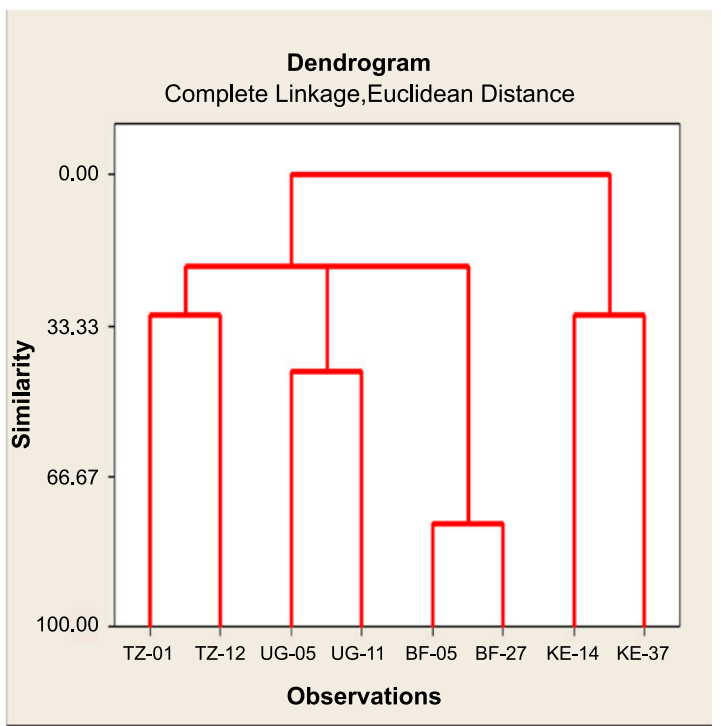

Fig. 1. Genetic relationship among the eight isolates. A. Electrophoresis image of random amplified polymorphic DNA amplification with primer P-01 separated in a $1.4 \%$ agarose gel. Amplifications and gel electrophoresis were repeated three times for each primer and identical results were obtained. Only the clearly amplified polymorphic bright bands were analyzed. Numbers at the top correspond to isolates: lane $1=\mathrm{TZ}-01$, lane $2=\mathrm{TZ}-12$, lane $3=\mathrm{UG}-05$, lane $4=\mathrm{UG}-11$, lane $5=$ KE14, lane $6=\mathrm{KE}-37$, lane $7=\mathrm{BF}-05$, and lane $8=$ BF-27. Lane M =1-kb molecular marker. B. Dendrogram of the eight Magnaporthe oryzae isolates using Minitab's cluster analysis function computed with Euclidean Distance Complete Linkage. The scale indicates the genetic similarity in percentage.
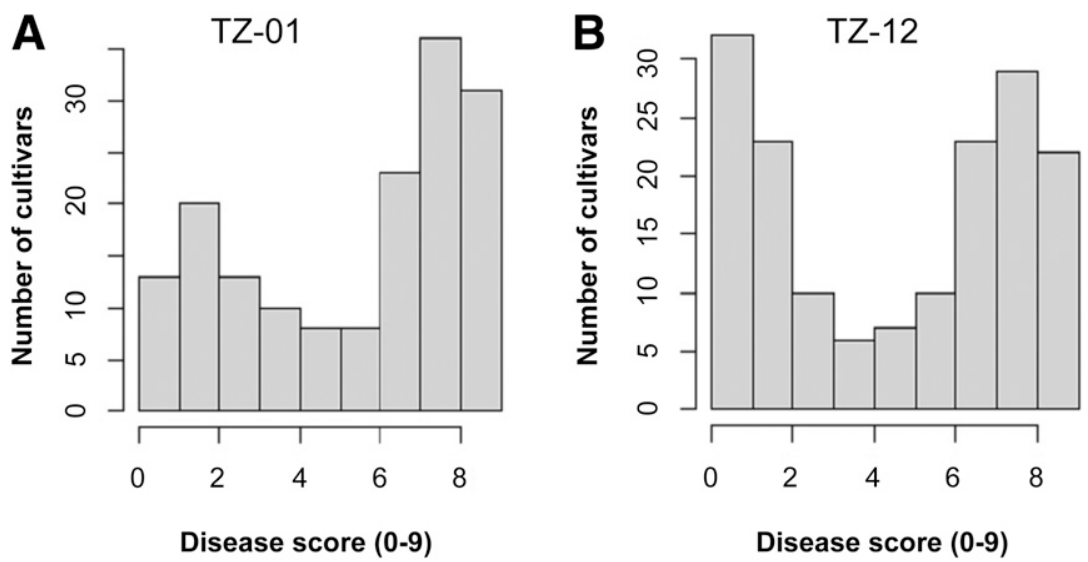

Fig. 2. Example of disease score distribution (0 to 9) of the rice diversity panel 1 (RDP1) cultivars inoculated with isolate A, TZ-01 and B, TZ-12. The inoculation experiment was repeated two times and the disease scores of the two biological replicates were similar. 
Philippines) -were grouped into one separate cluster, while isolate 0-249 (from India) was related (approximately 68\% similarity) to the two Kenyan isolates (KE-14 and KE-37) used in our study.

Identification of rice QTL associated with resistance to eight isolates. By using the $44 \mathrm{~K}-\mathrm{SNP}$ dataset $(36,900$ highquality SNP) (Zhao et al. 2011) and our blast inoculation data, we identified 31 nonredundant $R A B R$ (logarithm of odds [LOD] $\geq 3.5$ ) that were significantly associated with resistance against the eight $M$. oryzae isolates. $R A B R \_1, R A B R \_19, R A B R \_28, R A B R \_29$, and $R A B R \_30$ are located in the regions with the five previously mapped $R$ genes Pi27(t), Pi50, Piy(t), Pi34, and Pi43, respectively. RABR_2, and $R A B R \_11$ are located in regions with the previously cloned $R$ genes Pish and Pi21, respectively. The remaining $24 R A B R$ are novel candidate genes (Fig. 3). Detailed information about chromosome locations and candidate genes in the regions for all $31 R A B R$ is summarized in Supplementary Table S4. At least three $R A B R$ were associated with each of seven isolates but no $R A B R$ was identified for isolate BF-27. However, the $R A B R$ identified for the isolates from the same country were not the same. For example, no $R A B R$ was common between the two Kenyan isolates (KE-14 and KE-37) (Supplementary Fig. 6) or between the two Burkina Faso isolates (BF-05 and BF-27) (Supplementary Fig. 7). The two Tanzanian isolates (TZ-01 and TZ-12) had a total of $13 R A B R$ but only 3 in common (Fig. 3; Supplementary Fig. S8). The two Uganda isolates (UG-05 and UG-11) had a total of $17 R A B R$ and shared 5 (Figs. 3 and 4). Some similarity was evident in the $R A B R$ in Tanzanian and Ugandan isolates. TZ-01 shared four $R A B R$ with UG-05 and three with UG-11. UG-05 and UG-11 each shared six $R A B R$ with TZ-12. Of note, BF-05 (from West Africa) shared eight $R A B R$ with the four isolates from Tanzania and Uganda (East Africa). The two Kenyan (East Africa) isolates did not share any $R A B R$ with the other isolates.

The $31 R A B R$ are distributed across 10 of the 12 rice chromosomes. The highest number of $R A B R$ per chromosome was six (observed on chromosomes 2 and 4 ) while none was detected on chromosomes 3 or 7. Chromosomes 6 and 11 had four $R A B R$ each, chromosomes 1 and 5 had three $R A B R$ each, chromosomes 8 and 10 had two $R A B R$ each, and chromosomes 9 and 12 had one $R A B R$ each. In total, 13 $R A B R$ were associated with resistance to at least two isolates. Two $R A B R$ were associated with resistance to three isolates and three $R A B R$ were associated for resistance to four isolates. $R A B R \_2$, located on chromosome 1 , was strongly associated with resistance to five isolates. The SNP signals for the $R A B R \_2$ locus were the highest in response to isolate UG-05 $(P=9.52 \mathrm{E}-16, \mathrm{LOD}=13.5)(\mathrm{Fig} .4 \mathrm{~A})$.

We then searched the reference Nipponbare genomic sequence (MSU V7.0) using gene ontology terms to identify candidate $R$ genes associated with the $31 R A B R$. Annotation analysis of the $R A B R$ led to the identification of $36 R$ or $R$-related candidate genes. The 36 candidate genes can be categorized into eight main functional groups: NBS-LRR genes, NB-ARC domain genes, protein phosphorylation related genes, transcription factor genes, ubiquitination-related genes, DNA-binding genes, receptor-like protein kinase genes, and oxidase/reductase family genes. These results show that the identified $R A B R$ may have different biological functions associated with both qualitative and quantitative resistance against $M$. oryzae.

$\boldsymbol{R A B R} \mathbf{2}$ is linked to the Pish $\boldsymbol{R}$ gene. The strong association of $R A B R \_2$ with resistance to five of the eight isolates prompted us to perform a detailed analysis of the region. Based on the GWAS results, there were $18 \mathrm{SNP}$ with a LOD value $>3.5$ corresponding to $R A B R \_2$. Sequence analysis showed that the cloned $R$ gene Pish is closely linked to the $R A B R \_2$ region. A genome analysis by Takahashi et al. (2010) revealed that Pish, along with other three highly conserved NBS-LRR paralogous genes, belongs to the NBS-LRR class of $R$ genes (Takahashi et al. 2010). Pish was first discovered by Imbe and Matsumoto (1985). Using the sequences of the cloned $R$ gene $P i s h$ as a reference, we designed six primer pairs (Supplementary Table S5) to amplify the sequence of the candidate gene in 10 resistant and 15 susceptible cultivars that were identified in our pathogenicity assay. PCR amplifications revealed that a fragment was generated with all primer pairs for all of the 10 resistant cultivars but for none of the 15 susceptible cultivars (Fig. 5A). As a control, amplification was observed in all 25 cultivars when the primer pair N10F $+\mathrm{N} 10 \mathrm{R}$ was used (Fig. 5A). The relative position of the amplified fragments of the six primer pairs in the Pish coding region is shown in Figure 5B. These results suggest that $R A B R \_2$ might be a new allele of the Pish gene.

\section{DISCUSSION}

Rice blast is becoming an important disease in many ricegrowing areas in Africa because of the lack of highly resistant rice

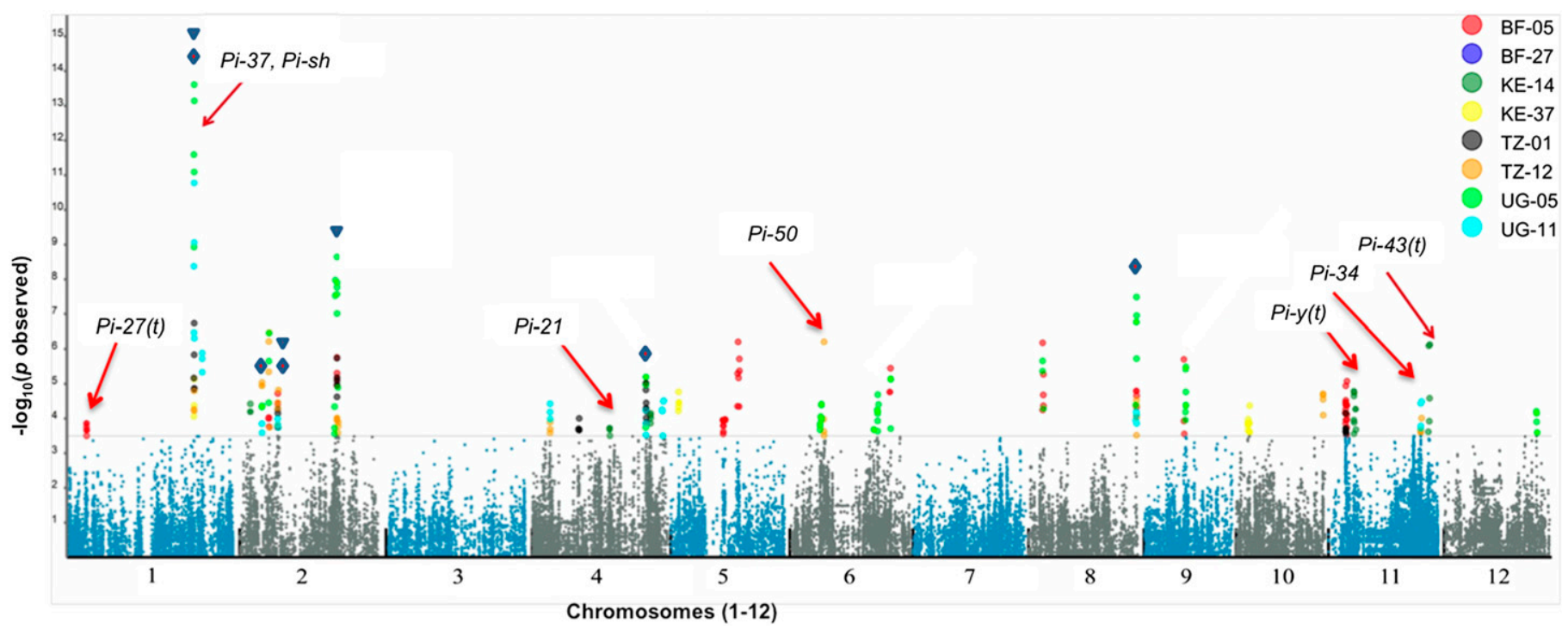

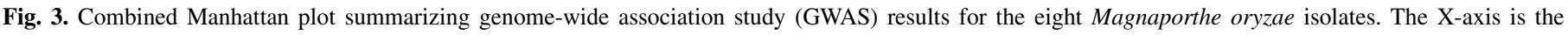

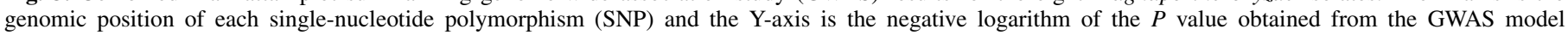

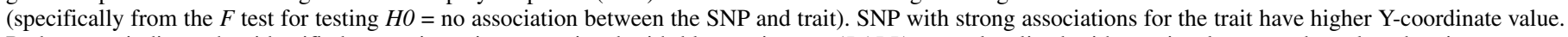

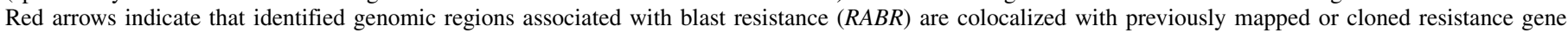

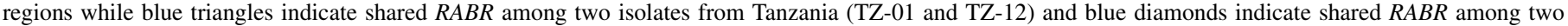
isolates from Uganda (UG-05 and UG-11). 
cultivars, increased fertilizer application, and recent changes in climatic conditions. Therefore, germplasm that is resistant to the prevailing African M. oryzae populations is urgently needed. In this study, we used two subpopulations (indica and temperate japonica) in RDP1 to map the $R$ genes and QTL for resistance to eight diverse isolates from four African countries. We identified $31 R A B R$ involved in resistance to these isolates. Among them, $42 \%$ are associated with resistance to more than one isolate, and $R A B R \_2$ is associated with resistance to five isolates. These findings suggest that some $R A B R$ may contain multiple $R$ genes or QTL, or a single locus in the region may confer resistance to multiple isolates. Seven of the $R A B R$ are colocalized with the blast resistance loci previously identified in the articles by Wang et al. (2014a) and Kang et al. (in press). Specifically, five $R A B R\left(R A B R \_1, R A B R \_19, R A B R \_28, R A B R \_29\right.$, and $R A B R \_30$ ) are closely related to the $L A B R$ previously reported by Kang et al. (in press), and $R A B R-1$ and $R A B R-28$ are also reported by Wang et al. (2014a). In all, $24 R A B R$ identified in this study are new. These results suggest that many of the rice loci associated with resistance against African populations may be different from the loci with resistance against non-African populations of M. oryzae. Further fine mapping will help us to detect the precise physical locations of these $31 R A B R$ in the rice genome and to determine

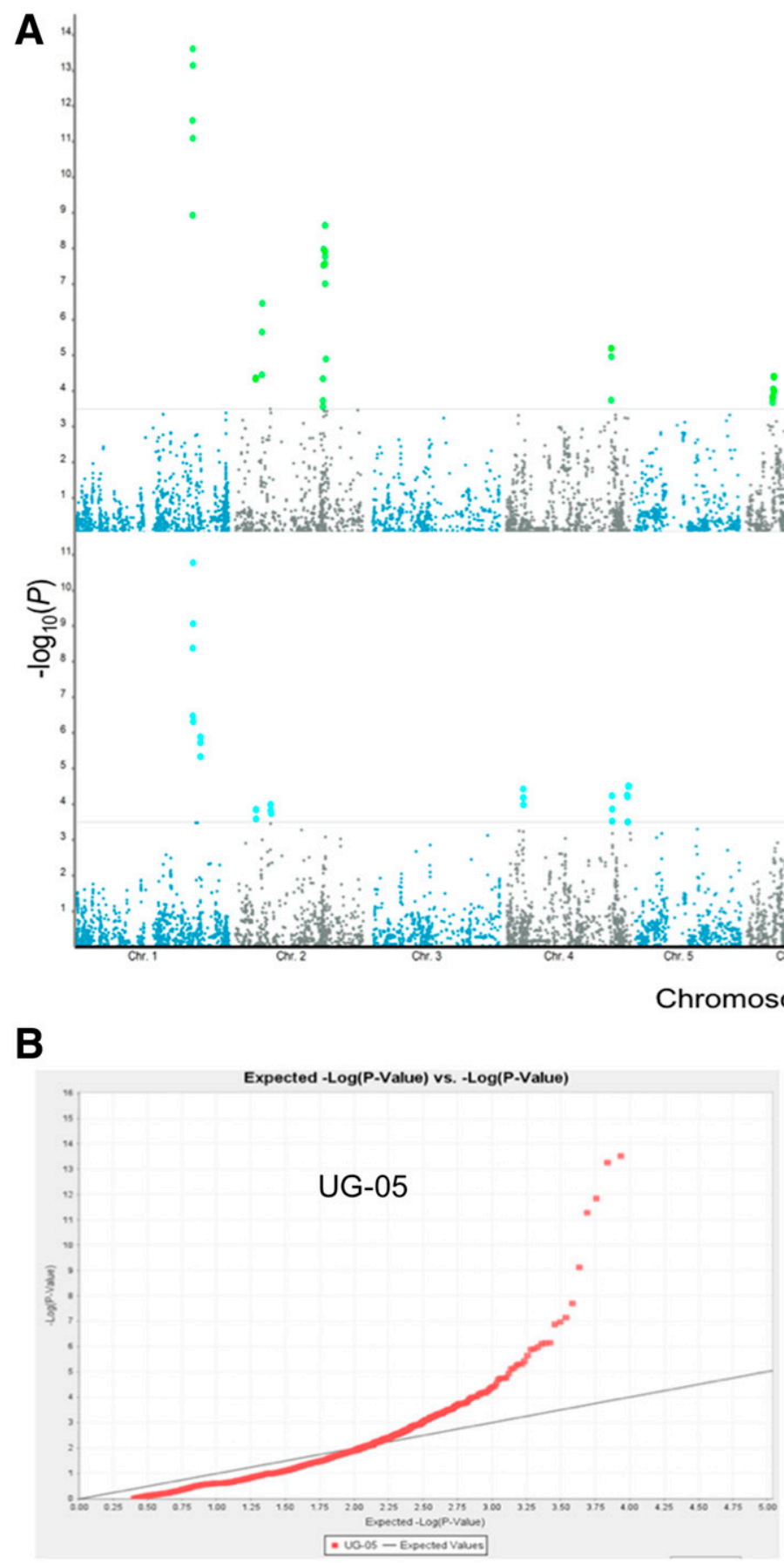

UG-05

UG-11

Fig. 4. Genome-wide association analysis results of the rice diversity panel 1 (RDP1) cultivars to two Ugandan isolates. A, Manhattan plots that summarize the results for two Ugandan isolates (UG-05 and UG-11). The X-axis is the genomic position of each single-nucleotide polymorphism (SNP) and the Y-axis is the negative logarithm of the $P$ value obtained from the genome-wide association study (GWAS) model (specifically from the $F$ test for testing $H O=$ no association between the SNP and trait). SNP with strong associations for the trait (blast disease resistance) have higher Y-coordinate value. B, Q-Q plots that shows fitness of the GWAS analysis model for the two isolates. The X-axis corresponds to the expected values of negative logarithm of $P$ and the $\mathrm{Y}$-axis corresponds to the observed values of negative logarithm of $P$. 

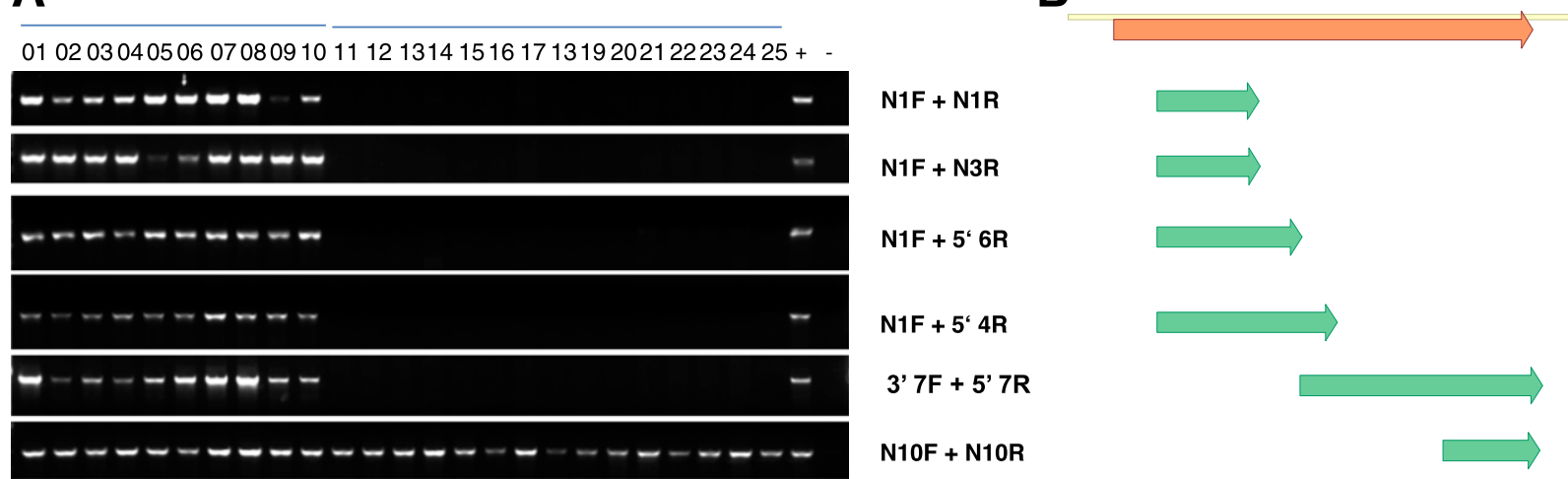

Fig. 5. Gel images of the amplified Pish gene fragments and the regions of designed primers used for amplification. A, Twenty-five temperate japonica rice cultivars were used in the polymerase chain reaction analysis. The primer sequence can be found in Supplementary Table S5. Lane 01 to 10 are varieties resistant to blast and lane 11 to 25 are varieties susceptible to blast while lane (+) is Nipponbare DNA as a positive control and lane (-) is water as negative control. B, Schematic diagram showing the location of each amplicon (primer) in the Pish gene coding region. The molecular weight for the six primers are N1F $+\mathrm{N} 1 \mathrm{R}=938$ bp, N1F+N3R $=952 b p, N 1 F+5^{\prime} 6 R=1,336 b p, N 1 F+5^{\prime} 4 R=1,661 b p, 3^{\prime} 7 F+5^{\prime} 7 R=2,343 b p$, and N10F $+N 10 R=895 b p$.

their relationship to other known $R$ and QTL genes effective against non-African populations of $M$. oryzae.

Durable resistance to $M$. oryzae is a complex trait and involves both complete and partial $R$ genes. In a well-known example, the durably resistant upland rice 'Moroberekan' contains two $R$ genes (Pi5 and Pi7) and 10 QTL (Wang et al. 1994). Recent GWAS have also shown that resistance to $M$. oryzae isolates in China, South America, India, Philippines, and Korea is controlled by multiple loci with $R$ genes and minor QTL genes (Liu et al. 2013) In this study, we inoculated 162 RPD1 cultivars with eight $M$. oryzae isolates from four African countries. Approximately one-third of the $R A B R$ had LOD scores $\geq 5.0$. The effects of these $R A B R$ on resistance to $M$. oryzae were as strong as those of $R$ genes. The remaining two-thirds of the $R A B R$ had low LOD scores and are considered to be QTL. Our results confirm that resistance to M. oryzae populations in Africa is complex and is controlled by both major and minor genes. Although the functions of the candidate QTL associated with blast resistance require confirmation, detection of loci associated with partial resistance against African populations of $M$. oryzae provides starting materials for detailed molecular analysis. In addition, some of the SNP markers in those $R A B R$ with high LOD scores $(\geq 5.0)$ can be used in marker-aided selection of blast-resistant cultivars in Africa.

Among the $R A B R$ identified in this study, $R A B R \_2$ on chromosome 1 has the strongest association with blast resistance. Our search of the reference Nipponbare genomic sequence revealed that $R A B R \_2$ is colocalized with the $R$ gene Pish, which encodes an NBS-LRR disease-resistance protein (Kang et al. in press; Takahashi et al. 2010). The PCR amplification of the RABR_2related candidate gene in resistant and susceptible cultivars confirmed the association of the locus with resistance. $R A B R \_2$ is involved in resistance to five isolates from East Africa. Two of these isolates are from Tanzania (TZ-01 and TZ-12), two are from Uganda (UG-05 and UG-11), and one is from Kenya (KE-37). However, $R A B R \_2$ is not associated with resistance to either of the two isolates from Burkina Faso (West Africa). These results suggest that $R A B R \_2$ is a good candidate $R$ gene for control of rice blast in East Africa but not in West Africa.

We found that 11 cultivars are highly resistant (disease score $\leq$ 2.0) to all eight of the tested isolates of M. oryzae from Africa. Among them, six are indica types and five are temperate japonica types. These varieties may contain multiple $R$ genes or QTL that are effective against African $M$. oryzae populations. Genetic crosses are being made to map the $R$ genes and QTL in these cultivars. Crossing these resistant rice cultivars with highly susceptible but popular African cultivars will facilitate the breeding of resistance against rice blast in Africa.

\section{ACKNOWLEDGMENTS}

This project was supported, in part, by grants from the SCPRID program of BBSRC and BM Gates Foundation, Innovative Agricultural Research Initiative of the USAID, and United States Department of Agriculture (USDA) National Institute of Food and Agriculture Hatch Project. The RDP1 seed were obtained from the Genetic Stocks-Oryza Collection laboratory at the USDA Dale Bumpers National Rice Research Center.

\section{LITERATURE CITED}

Abdurakhmonov, I. Y., and Abdukarimov, A. 2008. Application of association mapping to understanding the genetic diversity of plant germplasm resources. Int. J. Plant Genomics 2008:Article 574927. doi:10.1155/2008/574927

Bashir, U., Mushtaq, S., and Akhtar, N. 2014. First report of Alternaria metachromatica from Pakistan causing leaf spot of tomato. Pak. J. Agric. Sci. 51:305-308.

Bourett, T. M., and Howard, R. J. 1990. In vitro development of penetration structures in the rice blast fungus Magnaporthe grisea. Can. J. Bot. 68: 329-342.

Bradbury, P. J., Zhiwu, Z., Dallas, E. K., Terry, M. C., Yogesh, R., and Edward, S. B. 2007. TASSEL: Software for association mapping of complex traits in diverse samples. Bioinformatics 23:2633-2635.

Buckler, E. S., Holland, J. B., Bradbury, P. J., Acharya, C. B., Brown, P. J., Browne, C., Ersoz, E., Flint-Garcia, S., Garcia, A., and Glaubitz, J. C. 2009. The genetic architecture of maize flowering time. Science 325:714-718.

Christiansen, T., Foy, B. D., Wall, L., and Orwant, J. 2012. Programming Perl: Unmatched Power for Text Processing and Scripting. O'Reilly Media, Inc., Sebastopol, CA.

Eizenga, G. C., Ali, M., Bryant, R. J., Yeater, K. M., McClung, A. M., and McCouch, S. R. 2013. Registration of the rice diversity panel 1 for genomewide association studies. J. Plant Regist. 8:109-116.

FAO. 2012. The State of Food Insecurity in the World 2012: Economic growth is necessary but not sufficient to accelerate reduction of hunger and malnutrition. FAO, Rome.

Govarthanan, M., Guruchandar, A., Arunapriya, S., Selvankumar, T., and Selvam, K. 2011. Genetic variability among Coleus sp. studied by RAPD banding pattern analysis. Int. J. Biotechnol. Mol. Biol. Res. 2:202-208.

Habarurema, I., Asea, G., Lamo, J., Gibson, P., Edema, R., Séré, Y., and Onasanya, R. O. 2012. Genetic analysis of resistance to rice bacterial blight in Uganda. Afr. Crop Sci. J. 20:105-112.

Henderson, C. R. 1975. Best linear unbiased estimation and prediction under a selection model. Biometrics 31:423-447.

Huang, X., Wei, X., Sang, T., Zhao, Q., Feng, Q., Zhao, Y., Li, C., Zhu, C., Lu, T., Zhang, Z., Li, M., Fan, D., Guo, Y., Wang, A., Wang, L., Deng, L., Li, W., Weng, Q., Liu, K., Huang, T., Zhou, T., Jing, Y., Li, W., Lin, Z., Buckler, E. S., Qian, Q., Zhang, Q., Li, J., and Han, B. 2010. Genome-wide association studies of 14 agronomic traits in rice landraces. Nat. Genet. 42:961-967.

Imbe, T., and Matsumoto, S. 1985. Inheritance of resistance of rice varieties to the blast fungus strains virulent to the variety "Reiho". Jpn. J. Breed. 35: 332-339. doi:10.1270/jsbbs 1951.35 .332

IRRI. 2013. World Rice Statistics. International Rice Research Institute, Los Baños, Philippines. 
Jia, G., Huang, X., Zhi, H., Zhao, Y., Zhao, Q., Li, W., Chai, Y., Yang, L., Liu, K., and Lu, H. 2013. A haplotype map of genomic variations and genomewide association studies of agronomic traits in foxtail millet (Setaria italica). Nat. Genet. 45:957-961.

Kang, H., Yue, W., Shasha, P., Yanli, Z., Yinghui, X., Dan, W., Shaohong, Q., Zhiqiang, L., Shuangyong, Y., Zhilong, W., Wende, L., Yuese, N., Pavel, K., Hei, L., Jason, M., Susan, R. M., and Wang, G. L. Dissection of the genetic architecture of rice resistance to the blast fungus Magnaporthe oryzae. Mol. Plant Pathol. In press. doi:10.1111/mpp. 12340

Kump, K. L., Bradbury, P. J., Wisser, R. J., Buckler, E. S., Belcher, A. R., Oropeza-Rosas, M. A., Zwonitzer, J. C., Kresovich, S., McMullen, M. D., and Ware, D. 2011. Genome-wide association study of quantitative resistance to southern leaf blight in the maize nested association mapping population. Nat. Genet. 43:163-168.

Li, H., Peng, Z., Yang, X., Wang, W., Fu, J., Wang, J., Han, Y., Chai, Y., Guo, T., and Yang, N. 2012. Genome-wide association study dissects the genetic architecture of oil biosynthesis in maize kernels. Nat. Genet. 45:43-50.

Lipka, A. E., Tian, F., Wang, Q., Peiffer, J., Li, M., Bradbury, P. J., Gore, M. A., Buckler, E. S., and Zhang, Z. 2012. GAPIT: Genome association and prediction integrated tool. Bioinformatics 28:2397-2399.

Liu, W., Liu, J., Triplett, L., Leach, J. E., and Wang, G. L. 2014. Novel insights into rice innate immunity against bacterial and fungal pathogens. Annu. Rev. Phytopathol. 52:213-241.

Liu, Y., Liu, B., Zhu, X., Yang, J., Bordeos, A., Wang, G., Leach, J. E., and Leung, H. 2013. Fine-mapping and molecular marker development for Pi56(t), a NBS-LRR gene conferring broad-spectrum resistance to Magnaporthe oryzae in rice. Theor. Appl. Genet. 126:985-998.

Luzi-Kihupi, A., Zakayo, J., Tusekelege, H., Mkuya, M., Kibanda, N., Khatib, K., and Maerere, A. 2009. Mutation breeding for rice improvement in Tanzania. Pages 385-387 in: Induced Plant Mutations in the Genomics Era. Q. Y. Shu, ed. Food and Agriculture Organization of the United Nations, Rome.

Maclean, J. L., and Dawe, D. C. 2002. Rice almanac: Source book for the most important economic activity on earth. CAB International, Wallingford, UK, in association with the International Rice Research Institute, Los Banos, the Philippines.

Mew, T. W., Leung, H., Savary, S., Vera Cruz, C. M., and Leach, J. E. 2004. Looking ahead in rice disease research and management. Crit. Rev. Plant Sci. 23:103-127.

Morris, G. P., Ramu, P., Deshpande, S. P., Hash, C. T., Shah, T., Upadhyaya, H. D., Riera-Lizarazu, O., Brown, P. J., Acharya, C. B., and Mitchell, S. E. 2013. Population genomic and genome-wide association studies of agroclimatic traits in sorghum. Proc. Natl. Acad. Sci. USA 110:453-458.

Mundt, C. C. 2014. Durable resistance: A key to sustainable management of pathogens and pests. Infect. Genet. Evol. 27:446-455.

Muthayya, S., Sugimoto, J. D., Montgomery, S., and Maberly, G. F. 2014. An overview of global rice production, supply, trade, and consumption. Ann. N. Y. Acad. Sci. 1324:7-14.

Nayar, N. M. 2014. Rice in Africa. Pages 1-7 in: Encyclopaedia of the History of Science, Technology, and Medicine in Non-Western Cultures. H. Selin, ed. Springer, Dordrecht, the Netherlands.

Park, C.-H., Chen, S., Shirsekar, G., Zhou, B., Khang, C. H., Songkumarn, P., Afzal, A. J., Ning, Y., Wang, R., Bellizzi, M., Valent, B., and Wang, G.-L. 2012. The Magnaporthe oryzae effector AvrPiz-t targets the RING E3 Ubiquitin Ligase APIP6 to suppress pathogen-associated molecular pattern-triggered immunity in rice. Plant Cell 24:4748-4762.

Poland, J. A., Bradbury, P. J., Buckler, E. S., and Nelson, R. J. 2011. Genomewide nested association mapping of quantitative resistance to northern leaf blight in maize. Proc. Natl. Acad. Sci. USA 108:6893-6898.
Ribot, C., Hirsch, J., Balzergue, S., Tharreau, D., Nottéghem, J.-L., Lebrun, M.-H., and Morel, J.-B. 2008. Susceptibility of rice to the blast fungus, Magnaporthe grisea. J. Plant Physiol. 165:114-124.

Savary, S., Horgan, F., Willocquet, L., and Heong, K. 2012. A review of principles for sustainable pest management in rice. Crop Prot. 32:54-63.

Séré, Y., Fargette, D., Abo, M. E., Wydra, K., Bimerew, M., Onasanya, A., and Akator, S. K. 2013. Managing the major diseases of rice in Africa. Pages 213-228 in: Realizing Africa's Rice Promise. M. C. S. Wopereis, D. E. Johnson, N. Ahmadi, E. Tollens, and A. Jalloh, eds. CAB International, Wallingford, UK.

Singh, S., Sidhu, J. S., Huang, N., Vikal, Y., Li, Z., Brar, D. S., Dhaliwal, H. S., and Khush, G. S. 2001. Pyramiding three bacterial blight resistance genes (xa5, xa13 and Xa21) using marker-assisted selection into indica rice cultivar PR106. Theor. Appl. Genet. 102:1011-1015.

Takahashi, A., Hayashi, N., Miyao, A., and Hirochika, H. 2010. Unique features of the rice blast resistance Pish locus revealed by large scale retrotransposon-tagging. BMC Plant Biol. 10:175.

Tharreau, D., Fudal, I., Andriantsimialona, D., Utami, D., Fournier, E., Lebrun, M.-H., and Nottéghem, J.-L. 2009. World population structure and migration of the rice blast fungus, Magnaporthe oryzae. Pages 209-215 in: Advances in Genetics, Genomics and Control of Rice Blast Disease. Springer, Dordrecht, the Netherlands.

Tian, F., Bradbury, P. J., Brown, P. J., Hung, H., Sun, Q., Flint-Garcia, S., Rocheford, T. R., McMullen, M. D., Holland, J. B., and Buckler, E. S. 2011. Genome-wide association study of leaf architecture in the maize nested association mapping population. Nat. Genet. 43:159-162.

Wang, C., Yang, Y., Yuan, X., Xu, Q., Feng, Y., Yu, H., Wang, Y., and Wei, X. 2014a. Genome-wide association study of blast resistance in indica rice. BMC Plant Biol. 14:311.

Wang, G. L., Mackill, D. J., Bonman, J. M., McCouch, S. R., Champoux, M. C., and Nelson, R. J. 1994. RFLP mapping of genes conferring complete and partial resistance to blast in a durably resistant rice cultivar. Genetics 136:1421-1434.

Wang, X., Lee, S., Wang, J., Ma, J., Bianco, T., and Jia, Y. 2014b. Current advances on genetic resistance to rice blast disease. Pages 195-217 in: Rice-Germplasm, Genetics and Improvement. W. Yan and J. Bao, eds. InTech, Rijeka, Croatia.

Wang, Y., Wang, D., Deng, X., Liu, J., Sun, P., Liu, Y., Huang, H., Jiang, N., Kang, H., Ning, Y., Wang, Z., Xiao, Y., Liu, X., Liu, E., Dai, L., and Wang, G. L. 2012. Molecular mapping of the blast resistance genes Pi2-1 and Pi51(t) in the durably resistant rice 'Tianjingyeshengdao'. Phytopathology 102: 779-786.

Williams, J. G. K., Kubelik, A. R., Livak, K. J., Rafalski, J. A., and Tingey, S. V. 1990. DNA polymorphisms amplified by arbitrary primers are useful as genetic markers. Nucleic Acids Res. 18:6531-6535.

Zeigler, R. S., Leong, S. A., and Teng, P. S. 1994. Rice Blast Disease. CAB International, Wallingford, UK, in association with the International Rice Research Institute, Los Banos, Philippines.

Zhao, K., Tung, C. W., Eizenga, G. C., Wright, M. H., Ali, M. L., Price, A. H., Norton, G. J., Islam, M. R., Reynolds, A., Mezey, J., McClung, A. M., Bustamante, C. D., and McCouch, S. R. 2011. Genome-wide association mapping reveals a rich genetic architecture of complex traits in Oryza sativa. Nat. Commun. 2:Article 1467. doi:10.1038/ ncomms 1467

Zhu, X. Y., Chen, S., Yang, J. Y., Zhou, S. C., Zeng, L. X., Han, J. L., Su, J., Wang, L., and Pan, Q. H.. 2012. The identification of Pi5O(t), a new member of the rice blast resistance Pi2/Pi9 multigene family. Theor. Appl. Genet. 124:1295-1304. 